\title{
MENINGOENCEFALITE POR BACTÉRIA DO GENERO ESCHERICHIA EM SEPTUAGENÁRIO. TRATAMENTO PELO CLORANFENICOL INTRATECAL E MUSCULAR
}

\author{
HaRry BRaNDI DiNIZ * \\ ARNALDO BENINI *
}

Duplo aspecto tornou de interêsse a publicação dêste caso de meningoencefalite por $E$. coli: primeiro, o fato de se tratar de paciente de idade avançada; segundo, o de se obter a cura em tempo relativamente muito curto - 23 dias - com ótima evolução clínica.

De fato a meningite pelo $E$. coli não é comum, sendo mais freqüente no recém-nascido e rara no adulto ${ }^{1,3,4,10,21,23}$. Neal ${ }^{15}$, em revisão da literatura feita em 1926, encontrou sòmente 42 casos publicados de meningite a $E$. coli. Barrett e col. ${ }^{4}$ apresentaram dois casos de meningite a coli, em crianças, tratados com sulfa e derivados; êstes autores fizeram revisão da literatura das meningites a $E$. coli até 1941, verificando apenas 108 casos, dos quais $60 \%$ em crianças com menos de 3 meses de idade, $29 \%$ de 3 meses a 25 anos, $6 \%$ dos 25 anos aos 50 anos e $5 \%$ dos 50 anos aos 75 anos; os indices de mortalidade nestes grupos etários foram, respectivamente, $81 \%$, $62 \%, 85 \%, 83 \%$. Shields ${ }^{18}$ relatou que, em 10 anos, entre 776 casos de meningites, não encontrou nenhum devido a $E$. coli. Guy e Legerton ${ }^{12}$, revendo seu material, encontraram 3 casos de meningites por $E$. coli, num total de 95 meningites purulentas. Smith ${ }^{19}$, revendo a incidência de meningite purulenta em crianças, num periodo de 10 anos, encontrou 19 casos devidos a $E$. coli; dêstes 19 casos, dos quais 12 foram fatais, todos os pacientes tinham menos de 1 ano de idade e sendo que 13 dêles tinham menos de 1 mês. Watson ${ }^{21}$, estudando 45 casos de meningites purulentas no primeiro mês de vida, verificou que bacilos do grupo coli eram responsáveis em $73 \%$ do total.

Em nasso Serviço, igualmente, a meningite por $E$. coli é bastante rara tanto em crianças como adultos. Num total de 698 casos de meningites, no periodo de 1938 a 1958, encontramos sòmente dois casos em crianças, respectivamente, de 2 e de 6 meses de idade; em adulto, apenas encontramos o caso que agora relatamos.

Por outro lado, a evolução fatal nesta moléstia devia-se ao fato de não ser seu agente etiológico sensível aos antibióticos comuns. Sòmente com o

Trabalho do Serviço de Neurologia da Escola Paulista de Medicina (Prof. Paulino W. Longo). "Assistente. 
aparecimento de antibióticos de largo espectro ${ }^{22}$ é que se conseguiu algum avanço neste sentido. Alexander ${ }^{1}$ e Pease e Alexander ${ }^{16}$ comunicaram dois casos de meningite a $E$. coli em indivíduos adultos, tratados com sucesso pela estreptomicina. Gomes de Mattos, Brandi e Brandi ${ }^{11}$ trataram um caso de meningite a $E$. coli em criança, com a associação sulfadiazina-penicilina. Mais recentemente, o cloranfenicol mostrou-se o mais eficaz contra o bacilo coli. Brasil Pereira da Silva ${ }^{17}$ e Hanbery ${ }^{13}$, o primeiro nas moléstias intestinais dos lactentes e o segundo nas meningites a $E$. coli, confirmaram as qualidades terapêuticas do cloranfenicol. Faucon e Rajaonera ${ }^{9}$ publicaram um caso de cura de meningite a $E$. coli pelo cloranfenicol, em criança de 6 meses. Fairbrother e Martyn 8 mostraram, em testes de laboratório, que o cloranfenicol é um dos antibióticos mais eficazes contra a $E$. coli. Hanbery e Ajmone Marsan ${ }^{14}$, em experiências efetuadas em gatos e controladas pelo electrencefalograma, mostraram ser o cloranfenicol o menos irritante dos antibióticos sôbre o córtex e meninges, podendo pois ser administrado por via intra-raqueana. Trindade e Nastari ${ }^{20}$, Anderson e Ellis ${ }^{2}$ e Bartolozzi e col. ${ }^{5}$, injetaram uma suspensão microcristalina de cloranfenicol, por via intratecal em pacientes portadores de meningite e observaram que não houve reações secundárias ao medicamento.

A obtenção de um sal sódico do ester succínico de cloranfenicol *, solúvel em sôro fisiológico e em água destilada, aumentou muito a maleabilidade dêste antibiótico, facilitando sua administração e absorção, permitindo ministrá-lo fàcilmente por diversas vias, inclusive a intra-raqueana. Mais recentemente Bulgarelli e Corradi $^{6}$ fizeram testes de tolerância com o sal sódico, isto é, o succinato de cloranfenicol, por via intratecal em cães e não observaram quaisquer reações secundárias; em face disto, confirmaram a tolerância dêste medicamento, quando introduzido por via intratecal, em 6 casos de meningite tuberculosa. Piazza e Ballerini ' , também recentemente, empregaram o succinato de cloranfenicol intratecal. em 6 pacientes portadores de meningite não especificada.

\section{OBSERVAÇAO}

A.P.A., com 76 anos, brasileiro, casado. Em 6-6-58 apresentou um quadro agudo de infecção gastrintestinal, com febre, vômitos, cólicas abdominais, disenteria e mal-estar. No $4^{\circ}$ dia, já com remissão dêsse quadro, foi acometido de cefaléia ligeira e inquietação que progrediu nos dias subseqüentes, para 48 horas depois se apresentar agitado e com confusão mental. Ao exame clinico apresentava rigidez de nuca e sinais de Kernig e Brudzinski. O exame oftalmológico mostrou sòmente sinais de arteriosclerose e o exame do LCR evidenciou uma meningite purulenta por germes do gēnero Escherichia. Seu estado agravou-se sensivelmente nas 12 horas seguintes, apresentando-se em sonolência profunda, evoluindo para o coma. A terapêutica pelo succinato de cloranfenicol foi instituida por via intrarraqueana, na dose diária de $3 \mathrm{mg}$ por $\mathrm{kg}$ de pêso corporal, correspondendo a 2,5 $\mathrm{ml}$ de solução de succinato de cloranfenicol a $10 \%$, ou seja, cêrca de $250 \mathrm{mg}$ do sal. Além disso, ministramos diàriamente, por via intramuscular, $1 \mathrm{~g}$ do sal dividido em 4 doses de

\footnotetext{
* Quemicetina succinato, cedida pelo Laboratório Carlo Erba.
} 
$250 \mathrm{mg}$. Foi prescrita ao mesmo tempo medicação para atender ao estado geral do paciente.

No dia seguinte o paciente já apresentava sinais de ligeira melhora: o coma não era tão profundo, balbuciava palavras ininteligiveis e reagia aós estimulos externos com movimentos de desagrado e dor. A rigidez de nuca e a sonolência ainda persistiam. No $2^{\circ}$ dia após a instituição da terapêtica eram evidentes os sinais favoráveis. O paciente saiu do coma. Continuava, entretanto, semitorporoso, sonolento, mas já respondia com coerência a algumas perguntas. A rigidez de nuca e a cefaléia não eram tão intensas. Novo exame de LCR mostrou resultado mais ou menos idêntico ao anterior, porém já se observava uma elevação nitida da taxa de açúcar. No $3^{0}$ dia do tratamento as melhoras eram surpreendentes: o paciente estava consciente, relativamente bem orientado no tempo e no espaço, indagava sôbre o que tinha se passado e admirava estar num hospital. A cefaléia cedera totalmente, assim como a rigidez de nuca. Apresentava apenas ligeira irritabilidade. Nos dias subseqüentes, as melhoras se firmaram definitivamente. O paciente estava consciente, orientado e sem qualquer sintomatologia meningoencefálica. Na evolução para a cura, houve paralelismo entre estas melhoras clínicas e as do LCR, com nítida melhora do quadro inflamatório, assim como se tornou negativo o exame bacterioscópico.

\begin{tabular}{|c|c|c|c|c|c|c|c|}
\hline & $D a t a$ & $\begin{array}{c}\text { Células } \\
\mathrm{mm}^{3}\end{array}$ & $\begin{array}{c}\text { Neutróf. } \\
\%\end{array}$ & $\begin{array}{l}\text { Prot. } \\
\text { mg } \%\end{array}$ & $\begin{array}{l}\text { Clor. } \\
\text { mg \% }\end{array}$ & $\begin{array}{c}\text { Glicose } \\
\mathrm{mg} \%\end{array}$ & $\begin{array}{c}\text { Bactérias } \\
\text { por campo } \\
\text { (o.i.) }\end{array}$ \\
\hline $12-6-58$ & $\ldots \ldots \ldots$ & 5.173 & 94 & 225 & 690 & 8 & $+0,2$ \\
\hline $13-6-58$ & $\ldots \ldots$ & 5.525 & 88 & 305 & 702 & 31 & $+0,2$ \\
\hline $17-6-58$ & $\ldots \ldots \ldots \ldots$ & 187 & 16 & 134 & 731 & 74 & $+0,06$ \\
\hline $20-6-58$ & & 53 & 7 & 94 & 690 & 60 & Neg. \\
\hline $3-7-58$ & & 28 & 1 & 54 & 685 & 47 & Neg. \\
\hline $23-7-58$ & $\ldots \ldots \ldots$ & 8,8 & 0 & 51 & 714 & 53 & Neg. \\
\hline
\end{tabular}

Caso A.P.A. - Evoluçió das alterações do liqüido cefalorraqueano no decorrer do tratamento.

No $15 \%$ dia da terapêutica o paciente estava cilnicamente curado, porém, como o exame do LCR ainda não estivessee normalizado, muito embora a tendência fôsse para tal, suspendemos as aplicações intratecais de cloranfenicol, mantendo apenas as intramusculares. Demos alta hospitalar em 3-7-58, isto é, 23 dias após a internação. O exame neurológico nesta ocasião foi normal. Como um ũltimo exame do LCR efetuado em 23-7-58 fôsse quase normal, suspendemos definitivamente tôda a terapêtica antibiótica. Nesta data reexaminamos o paciente e verificamos que - mesmo não apresentava qualquer seqüela neurológica, assim como seu estado mental era perfeitamente normal. Um ano após, em junho de 1959, o paciente continuava perfeitamente bem, sem qualquer seqüela neuropsíquica e em plena atividade fisica e mental.

\section{RESUMO}

Os autores apresentam um caso grave de meningoencefalite, por Escherichia coli, em septuagenário tratado e curado por injeçōes intra-raqueanas e intramusculares de succinato de cloranfenicol. Trata-se de paciente com 
76 anos de idade e que após uma toxinfecção gastrintestinal aguda, apresentou um quadro de meningoencefalite, tendo o exame do líqüido cefalorraqueano mostrado um processo meningitico por $E$. coli. Foi instituída a terapêutica antibiótica pelo cloranfenicol, por via intratecal, na dose diária de $3 \mathrm{mg}$ por $\mathrm{kg}$ de pêso corporal, correspondendo a $2,5 \mathrm{ml}$ de solução de succinato de cloranfenicol a $10 \%$, ou seja $250 \mathrm{mg}$ do sal. Por via intramuscular foi utilizada a dose diária de $1 \mathrm{~g}$ de succinato de cloranfenicol dividida em 4 doses. Em 23 dias de tratamento houve cura clínica total, acompanhada de melhora nítida do quadro inflamatório do LCR e de negativação do exame bacterioscópico. O exame clínico do paciente um ano após revelou ausência de qualquer seqüela neuropsíquica.

\section{SUMMARY}

\section{"Eschirichia coli" meningitis in a 76 year-old patient successfully treated with cloramphenicol.}

Report of a severe case of meningoencephalitis on a seventy six year old patient, who was treated and cured by intra-thecal and intra-muscular injections of chloramphenicol. The clinical process of meningoencephalitis started after a gastro-intestinal toxic infection. The cerebrospinal fluid examination showed a meningitic process by $E$. coli. It was prescribed chloramphenicol therapy by intra-thecal way, in daily doses of $3 \mathrm{mg} / \mathrm{kg}$, corresponding to $2.5 \mathrm{ml}$ of chloramphenicol succinate solution at $10 \%$ or $250 \mathrm{mg}$ of the salt. At the same time, chloramphenicol succinate was administered by muscle in the daily dose of $1 \mathrm{~g}$ divided in four doses. After 23 days of treatment it was obtained clinical cure followed by improvement of the spinal fluid, which showed a decrease from 5,172 to 8 cells and complete negative bacterioscopic findings. After a one year follow-up the patient is quite well and is without neuro-psychiatric sequelae.

\section{REFERENCIAS}

1. ALEXANDER, J. A. - Meningitis due to Escherichia coli treated with streptomycin. J.A.M.A., 131(8):663, 1946. 2. ANDERSON, K. F.; ELLIS, F. G. - Intrathecal cloramphenicol in staphilococcal meningitis resistant to penicilin and streptomycin. Brit. M. J., 2:1067-1069, 1951. 3. BAKER, A. B. - Clinical Neurology. A. Hoeber-Harper Book, Nova York, 1955, pág. 633. 4. BARRETT, J. S.; RAMMELKAMP, C. H.; WORCESTER, J. - Meningitis due to Escherichia coli: report of two cases with recovery following chemotherapy; review of the literature and report of experimental studies. Am. J. Dis. Child., 63:41, 1942. 5. BARTOLOzZI, G.; CALANDI, C.; MILANI-COMPARETTI, A. - Cit. por Piazza e Ballerini 7. 6. BULGARELLI, R.; CORRADI, G. - Si puó inietare endorachide in cloroanfenicolo. Gazzetta Sanitaria (Milão), 25:33, 1945. 7. DI PIAZZA, P.; BALLERINI, A. - O cloranfenicol succinato intrarraqueano no tratamento das sindromes meningíticas. Gazeta Sanitária (Milão), 5-6:41, 1957. 8. FAIRBROTHER, R. W.; MARTYN, G. The laboratory control of antibiotic therapy. Lancet, 6682:516, 1951. 9. FAUCON, R.; RAJAONERA, F. - Meningite a Escherichia coli type 026 B6. Bull. Soc. Pathol. Éxotique, 50(5):633, 1957. 10. FORD, F. R. - Diseases of the Nervous System in 
Infancy, Childhood and Adolescence. Charles C. Thomas, Springfield, 1952, pág. 590. 11. GOMES DE MATTOS, A.; BRANDI, R.; BRANDI, A. J. - Meningite a colibacilo: um caso tratado com associação sulfadiazina-penicilina. Pediatria Prática, 17 (1-2), 1946. 12. GUY, E. G.; LEGERTON, C. W. - Cit. por Redondo, J. P. - Meningites Agudas. Salvat Editores, Barcelona, 1950. 13. HANBERY, J. W. - Present concept in the treatment of purulent meningitis. Neurology, 4:301, 1954.14. HANBERY, J. W.; AJMONE MARSAN, C. - Resumo in Arch. Neurol. a. Psychiat., 72:651, 1954. 15. NEAL, J. B. - Meningitis caused by bacilli of colon group. Am. J. M. Sc., 172:740-748, 1926. 16. PEASE, W.; ALEXANDER, J. T. — Cit. in Spiegel, E. A. - Progress in Neurology and Psychiatry. Grune a. Stratton, Nova York, 1954. 17. PEREIRA DA SILVA, W. B. - O emprêgo do succinato de cloranfenicol nas diarréias agudas do lactente. Departamento Estadual da Criança, São Paulo, 1958. 18. SHIELDS, W. P. - Meningitis due to Escherichia coli. J.A.M.A., 132(9): 514, 1946. 19. SMITH, E. - Purulent meningitis in infants and children: review of 409 cases. J. Pediat., 45:425-436, 1954. 20. TRINDADE, O.; NASTARI, F. Cloromicetina intrarraquidea no homem: seu emprêgo em um caso de meningite por Shiguela paradysenteriae. Rev. Paulista de Med., 36:369, 1950. 21. WATSON, D. G. - Purulent neo-natal meningitis: study of 45 cases. J. Pediat., 50:352, 1957. 22. WEIL, A. P.; STEMPEL, B. - Further studies on antibiotic sensitivity of microorganisms isolated in general hospital. Antibiotics \& Chemother., 3:1135-1140, 1953. 23. WILSON, K. S. A. - Neurology. Butterworth \& Co., Londres, 1954, pág. 31

Servico de Neurologia da Escola Paulista de Medicina - Caixa Postal 5496 São Paulo, Brasil. 